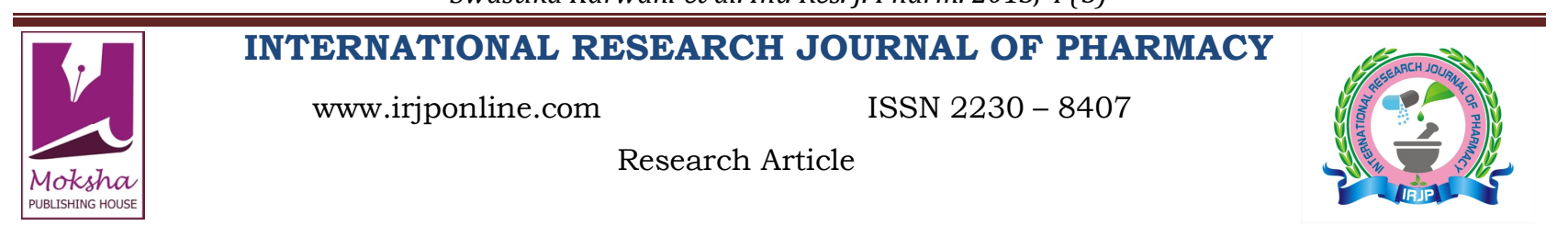

\title{
CHEMICAL MODIFICATION OF CHITOSAN AND FORMULATION OF ITS NANOPARTICLES FOR PROTEIN DRUG DELIVERY SYSTEM
}

Swastika Karwani ${ }^{1}$, Rabindra Nanda ${ }^{2}$ and Jyoti Nirmal ${ }^{3}$

Padmashree Dr. D. Y. Patil Institute of Pharmaceutical Research and Sciences, Pune, India

Email: swastikakarwani@yahoo.in

Article Received on: 10/03/13 Revised on: 01/04/13 Approved for publication: 03/05/13

DOI: $10.7897 / 2230-8407.04534$

IRJP is an official publication of Moksha Publishing House. Website: www.mokshaph.com

(C) All rights reserved.

\section{ABSTRACT}

The most common route of administration of proteins has been parenterals using invasive ways of administration but this route has many side effects like lack of patient compliance, cost, high drug levels etc. The development of an oral dosage form that improves the absorption of protein drugs is the most desirable formulation but one of the greatest challenges in the pharmaceutical field. The major barriers in developing oral formulations for peptides and proteins include poor intrinsic permeability, luminal and cellular enzymatic degradation and chemical and conformational stability. A number of innovative oral drug delivery approaches have been recently developed, including the drug entrapment within polymer nanoparticles. The various advantages of oral delivery of proteins are like ease of administration, can be used as cure in primary stages of disease eg. Thrombosis, no internal bleeding, patient compliance and economical Our formulation development approach is to develop the formulations targeted to bypass the stomach with an aim to release the drug in the intestine; with extended residence time in the GIT and for this polymer like Chitosan is used. To improve the lipophillic property of chitosan, to modify biodegradation pattern of polymer and for oral delivery of proteins (Insulin and serratiopeptidase), modification is done using lactic-acid and polyethyleneglycol by copolymerization. Keywords: Insulin, Serratiopeptidase, Lactic-Acid, Polyethyleneglycol and Chitosan

\section{INTRODUCTION}

Proteins also known as polypeptides are organic compounds made up of amino acids arranged in a linear chain and folded into a globular form. The amino acids in a polymer are joined together by the peptide bonds between the carboxyl and amino groups of adjacent amino acid residues. Serving as the basic structural molecule of all the tissues in the body, protein makes up nearly $17 \%$ of the total body weight. Insulin, Somatotropin Like other biological macromolecules proteins are essential parts of organisms and participate in virtually every process within cells. The oral route is considered to be the most convenient and desired route of drug delivery, especially when repeated or routine administration is necessary. Generally, peptides and proteins such as insulin cannot be administered via the oral route due to rapid enzymatic degradation in the stomach, inactivation and digestion by proteolytic enzymes in the intestinal lumen, and poor permeability across intestinal epithelium because of its high molecular weight and lack of lipophilicity. The oral bioavailability of most peptides and proteins therefore is less. Insulin is usually administered to diabetic patients through subcutaneous injection. However, the problems encountered with subcutaneous insulin injections are pain, allergic reactions, hyperinsulinemia, and insulin lipodystrophy around the injection site. Insulin if administered via the oral route will help eliminate the pain caused by injection, psychological barriers associated with multiple daily injections such as needle anxiety and possible infections. In light of the above distinct benefits, pharmaceutical technologists have been trying to design an oral delivery system for different proteins. Such is the interest in oral SRPT and Insulin delivery that some pharmaceutical companies are solely focused on $\mathrm{it}^{1-6}$. A number of different methods have been explored to improve the oral bioavailability of proteins. A common method, has been, the use of penetration enhancers, like detergents, fatty acids or bile salts which are meant to permeabilize the mucus and epithelial layers and open the intercellular tight junctions. Encapsulation of the protein within enteric capsules or nanospheres has also been used .In this present research work attempt has been made to develop oral dosage form for insulin using modified Chitosan polymer which is formed by copolymerization technique.

\section{MATERIALS AND METHODS}

Materials used

Insulin, Chitosan, Polyethylene glycols, Lactic acid, Sodium tripolyphosphate, Sodium Alginate and Anhydrous Calcium chloride

\section{Selection of polymer for modification}

Selection of polymer was done on the basis of solubility in water. Chitosan is a polysaccharide formed primarily of repeating units of b-(1-4)2-amino-2-deoxy-D-glucose (Dglucosamine). Generally, chitosan is soluble in aqueous medium in the presence of a small amount of acids such as $\mathrm{AcOH}$, lactic acid, $\mathrm{HCl}$ and so on. Though the chitosan dissolves in aqueous acidic medium below $\mathrm{pH}$ 6.5, it precipitates above this $\mathrm{pH}$ by the addition of alkali solution like aq. $\mathrm{NaOH}$. The application of chitosan was limited owing to the insolubility at neutral or high $\mathrm{pH}$ region. To improve the lipophilic property of chitosan, modification is required.

\section{Preparation of Acetylated chitosan copolymer: (C1)}

The reaction is involved between the $\mathrm{NH}_{2}$ groups of chitosan and $-\mathrm{OH}$ group of acetic acid and removal of water takes place. First, chitosan was dissolved in aqueous acetic acid $1 \%$. After that, the solution was stirred at $100^{\circ} \mathrm{C}$ to create a final solution of chitosan. The solution was placed in petri dishes overnight for film formation. The film obtained as final product, acetylated chitosan copolymer ${ }^{7}$.

Preparation of LA-g-chitosan copolymer: (C2)

The reaction is involved between the $\mathrm{NH}_{2}$ groups of chitosan and $-\mathrm{OH}$ group of lactic acid and removal of water takes 
place. First, chitosan was dissolved in a mixture of $1 \%$ acetic acid. Aqueous solution of $0.5 \%$ lactic acid was added into the chitosan solution. After that, the solution was stirred at $100^{\circ} \mathrm{C}$ to create a final solution of chitosan. The solution was placed in petri dishes overnight for film formation. The film obtained as final product, chitosan-g-LA copolymer ${ }^{8-10}$.

\section{Preparation of Pegylated chitosan: (C3)}

The reaction is involved between the $\mathrm{NH}_{2}$ group of chitosan and $-\mathrm{OH}$ group of PEG and removal of water takes place. First, chitosan was dissolved in a mixture of $1 \%$ acetic acid. Aqueous solution of $1 \%$ PEG was added into the chitosan solution. After that, the solution was stirred at $100^{\circ} \mathrm{C}$ to create a final solution of chitosan. The solution was placed in petri dishes overnight for film formation. The film obtained as final product, chitosan-g-PEG copolymer ${ }^{11-12}$.

\section{Preparation of Lactic acid and PEG-grafted-chitosan copolymer: (C4)}

The reaction is involved between the $\mathrm{NH}_{2}$ group of chitosan and -OH group of lactic acid and PEG and removal of water takes place. First, chitosan was dissolved in a mixture of $1 \%$ acetic acid. Aqueous solution of both $0.5 \%$ lactic acid and $1 \%$ PEG was added into the chitosan solution. After that, the solution was stirred at $100^{\circ} \mathrm{C}$ to create a final solution of chitosan. The solution was placed in petri dishes overnight for film formation. The film obtained as final product, chitosan-g-LA-PEG copolymer ${ }^{8-13}$.

\section{Formulation of nanoparticles}

Chitosan nanoparticles were prepared according to the ionic gelation of Chitosan with Pentasodium tripolyphosphate (TPP) anions. Plain chitosan and modified chitosan were used for formulating nanoparticles. Four types of samples were prepared:

I. Chitosan was dissolved in $1 \% \mathrm{v} / \mathrm{v}$ acetic acid aqueous solution at various concentrations $(0.5,1.0,1.5,2.0,2.5 \%$ w/v). [N1]

II. Chitosan was dissolved in $1 \% \mathrm{v} / \mathrm{v}$ acetic acid aqueous solution at various concentrations $(0.5,1.0,1.5,2.0,2.5 \%$ $\mathrm{w} / \mathrm{v})$ and $0.5 \% \mathrm{v} / \mathrm{v}$ lactic acid aqueous solution at concentration of 0.5 . [N2]

III. Chitosan was dissolved in $1 \% \mathrm{v} / \mathrm{v}$ acetic acid aqueous solution at various concentrations $(0.5,1.0,1.5,2.0,2.5 \%$ w/v) and $1 \% \mathrm{v} / \mathrm{v}$ PEG. [N3]

IV. Chitosan was dissolved in $1 \% \mathrm{v} / \mathrm{v}$ acetic acid aqueous solution at various concentrations $(0.5,1.0,1.5,2.0,2.5 \%$ $\mathrm{w} / \mathrm{v})$ and $0.5 \% \mathrm{v} / \mathrm{v}$ lactic acid aqueous solution at concentration of 0.5 and $1 \% \mathrm{v} / \mathrm{v}$ PEG. [N4]

Aqueous solution of TPP $5 \mathrm{ml}$ with concentration $(0.01 \%$ $\mathrm{w} / \mathrm{v}$ ) was added through a syringe needle into $10 \mathrm{ml}$ chitosan solution under stirring at room temperature. The phenomena observed were in aqueous solution. Nanoparticles were formed spontaneously upon incorporation of $5 \mathrm{ml}$ TPP solution into $10 \mathrm{ml}$ chitosan solution. The above nano solutions $\mathrm{N} 1, \mathrm{~N} 2, \mathrm{~N} 3$, and $\mathrm{N} 4$ were adjusted to $\mathrm{pH}$ 6.5-6.8.

\section{Percentage yield of chitosan nanoparticles}

Percentage yield of nanoparticles was calculated using the following formula

Percentage Yield $=$

Amount of nanoparticles obtained (mg) / Theoretical Amount $(\mathrm{mg}) \times 100$
Loading of protein on nanoparticles

The lyophylized nanoparticles $(100 \mathrm{mg}$ ) were resuspended in distilled water under ultrasonication at room temperature. The known amount of protein solution was incubated overnight in the nanoparticles suspension. The encapsulation efficiency and loading capacity of nanoparticles were determined by the separation of nanoparticles from the aqueous medium containing non-associated protein by centrifugation at $1400 \mathrm{rpm}$ for $10 \mathrm{~min}$. The amount of free protein in the supernatant was measured by Assay method.

The protein loading efficiency (LE) and the protein loading capacity (LC) of the nanoparticles were calculated as follows:

$$
\begin{aligned}
& \text { Loading Efficiency }(\%)= \\
& \text { Total amount of protein - free protein / Total amount of protein } \times 100 \\
& \text { Loading Capacity (\%) = } \\
& \text { Total amount of protein - free protein / Weight of nanoparticles } \times 100
\end{aligned}
$$

All measurements were performed in triplicate.

\section{Formulation of BEADS ${ }^{14-18}$}

Entrapment of chitosan nanoparticles loaded with protein in Alginate beads

Various concentrations of Sodium alginate solution were prepared in double distilled water and fixed amount $(100 \mathrm{mg})$ of chitosan nanoparticles loaded with protein were incorporated in the Sodium alginate solutions of various concentrations.

\section{Evaluation of uncoated beads \\ Appearance}

Surface morphology was observed by microscopy.

\section{Beads size analysis}

The dimensions of beads were measured with the help of Digital Vernier Calliper by taking 10 beads from each batch. Average size of bead was noted.

\section{Percentage yield of beads}

Percentage yield of beads was calculated using the following formula-

$$
\begin{aligned}
& \text { Percentage Yield }= \\
& \text { Amount of beads obtained }(\mathrm{mg}) / \text { Theoretical Amount }(\mathrm{mg}) \times 100
\end{aligned}
$$

\section{In-vitro Drug release studies in pH 6.8 PBS}

In-vitro Drug Release studies of protein loaded beads were carried out by using USP XXIII Dissolution Test Apparatus 1 (Basket method) at $37 \pm 0.5^{\circ} \mathrm{C}$ and $100 \mathrm{rpm}$ speed. The weighed amount of protein Loaded Beads were placed in the baskets and then submerged into $900 \mathrm{ml}$ dissolution flask containing 500ml of PBS pH 6.8 for $3 \mathrm{hrs}$. Aliquots of $2 \mathrm{ml}$ were withdrawn and replaced with the same volume of fresh solution at each different time intervals. Aliquots withdrawn were filtered through Whatman filter paper number 42 . The amount of drug released was analyzed by UV-visible spectrophotometric bio assay. The release studies were conducted in triplicates and mean values of cumulative \% drug release were plotted versus time ${ }^{19-20}$.

\section{Content uniformity}

Content Uniformity was determined by dissolving beads in pH 6.8 PBS for 5 hrs and UV absorbance was recorded to estimate the \% drug content. 
Swastika Karwani et al. Int. Res. J. Pharm. 2013, 4 (5)

Table 1: Optimization of parameters for preparation of alginate beads. $\mathrm{E}, \mathrm{F}, \mathrm{G}$ and $\mathrm{H}$ for Insulin

\begin{tabular}{|c|c|c|c|c|c|c|c|}
\hline \multirow{2}{*}{$\begin{array}{l}\text { Hardening } \\
\text { Time (min) }\end{array}$} & \multicolumn{4}{|c|}{ Sodium alginate $(\% \mathrm{w} / \mathrm{v})$} & $\mathrm{CaCl}_{2}(\% \mathrm{w} / \mathrm{v})$ & Drop Height(cm) & Drug loaded nanoparticles(mg) \\
\hline & 2 & 3 & 4 & 5 & \multirow{5}{*}{2} & \multirow[t]{5}{*}{5} & \multirow[t]{5}{*}{100} \\
\hline 5 & E1 & F1 & G1 & $\mathrm{H} 1$ & & & \\
\hline 10 & E2 & $\mathrm{F} 2$ & G2 & $\mathrm{H} 2$ & & & \\
\hline 15 & E3 & F3 & G3 & $\mathrm{H} 3$ & & & \\
\hline 20 & E4 & $\mathrm{F} 4$ & G4 & $\mathrm{H} 4$ & & & \\
\hline
\end{tabular}

Table 2: Oral glucose tolerance test in non diabetic rats

\begin{tabular}{|c|c|c|c|}
\hline Group $(n=6)$ & Treatment and Dose & Glucose Load & Evaluation Parameter \\
\hline I Control & Distilled water & \multirow{3}{*}{$\begin{array}{l}10 \% \text { Glucose solution ( } 2 \\
\text { g/kg, p.o) } 150 \text { min after } \\
\text { vehicle/drug }\end{array}$} & \multirow{3}{*}{$\begin{array}{l}\text { Plasma glucose }(\mathrm{mg} / \mathrm{dl}) \text { at } 0^{\text {th }}, 30^{\text {th }}, \\
90^{\text {th }} \text { and } 150^{\text {th }} \text { mins. and for test, } \\
\text { after a lag period of } 150 \text { mins. }\end{array}$} \\
\hline II Standard & Insulin (0.525IU/kg, S.C.) & & \\
\hline III, IV, V and VI Test & Insulin Beads (1.0 IU/kg, p.o.) & & \\
\hline
\end{tabular}

Table 3: Percent yield, loading efficiency and loading capacity of chitosan nanoparticles

\begin{tabular}{|c|c|c|c|c|c|c|}
\hline Batch Code & $\begin{array}{l}\text { Chitosan } \\
(1 \% \text { w/v) }\end{array}$ & $\begin{array}{c}\text { TPP } \\
(\% \mathrm{w} / \mathrm{v}) \\
\end{array}$ & $\begin{array}{c}\text { Chitosan: } \\
\text { TPP }\end{array}$ & $\begin{array}{c}\text { \% Yield* } \\
\text { (w/w) }\end{array}$ & $\begin{array}{c}E^{*} \\
(\% \mathbf{w} / w) \\
\end{array}$ & $\begin{array}{c}C^{*} \\
(\% \mathrm{w} / \mathrm{w}) \\
\end{array}$ \\
\hline $\begin{array}{c}\text { NANO } \\
\text { N1 } \\
\end{array}$ & $\mathrm{C} 1$ & \multirow[t]{4}{*}{0.1} & $2.5: 1$ & $60 \pm 0.08$ & $7.5 \pm 0.61$ & $50 \pm 0.11$ \\
\hline NANO N2 & $\mathrm{C} 2$ & & $5: 1$ & $73 \pm 0.38$ & $20.5 \pm 0.09$ & $56 \pm 0.19$ \\
\hline NANO N3 & $\mathrm{C} 3$ & & $7.5: 1$ & $80 \pm 0.38$ & $52 \pm 0.69$ & $65 \pm 0.37$ \\
\hline NANO N4 & $\mathrm{C} 4$ & & $10: 1$ & $87 \pm 0.04$ & $49 \pm 0.45$ & $79 \pm 0.56$ \\
\hline
\end{tabular}

* All values are expressed as mean, $\mathrm{n}=3$

Table 4: Percent yield, mean particle size and sphericity of beads of alginate

\begin{tabular}{|c|c|c|c|}
\hline Batch Code & \% Yield*(w/w) & Mean* Particle Size (mm) & Sphericity* \\
\hline A1, A2, A3, A4 & \multicolumn{3}{|c|}{ No Uniform Beads } \\
\hline B1 & \multicolumn{3}{|c|}{ Uneven beads } \\
\hline B2 & $98 \pm 0.17$ & $1.210 \pm 0.022$ & Spherical \\
\hline B3 & $96 \pm 0.25$ & $1.103 \pm 0.024$ & Spherical \\
\hline B4 & $96 \pm 0.19$ & Uneven beads & Spherical \\
\hline C1 & $97 \pm 0.19$ & $1.214 \pm 0.019$ & Spherical \\
\hline C2 & $96 \pm 0.57$ & $1.213 \pm 0.045$ & Spherical \\
\hline C3 & $98 \pm 0.73$ & $1.204 \pm 0.069$ & Spherical \\
\hline C4 & $98 \pm 0.18$ & Uneven beads & Spherical \\
\hline D1 & $97 \pm 0.22$ & $1.240 \pm 0.015$ & Spherical \\
\hline D2 & $97 \pm 0.29$ & $1.226 \pm 0.016$ & $1.221 \pm 0.018$ \\
\hline D3 & $* 416.011$ & \\
\hline D4 &
\end{tabular}

* All values are expressed as mean $\pm \mathrm{SD}, \mathrm{n}=3$

Table 5: \% Drug Release in pH 6.8 phosphate buffer from batches IB2-IB4

\begin{tabular}{|c|c|c|c|}
\hline \multirow{2}{*}{$\begin{array}{c}\text { Time } \\
\text { (mins) }\end{array}$} & *Batch Code. \% Drug Release in pH 6.8 phosphate buffer \\
\cline { 2 - 4 } & IB2 & IB3 & IB4 \\
\hline 0 & 0 & 0 & 0 \\
\hline 15 & $14.78 \pm 0.71$ & $12.31 \pm 0.19$ & $11.71 \pm 0.65$ \\
\hline 30 & $19.71 \pm 0.12$ & $17.65 \pm 0.71$ & $15.89 \pm 0.31$ \\
\hline 45 & $24.12 \pm 0.46$ & $21.78 \pm 048$ & $19.51 \pm 0.52$ \\
\hline 60 & $29.16 \pm 0.71$ & $27.78 \pm 0.11$ & $25.87 \pm 0.62$ \\
\hline 90 & $35.71 \pm 0.81$ & $33.98 \pm 0.45$ & $31.75 \pm 0.74$ \\
\hline 120 & $40.78 \pm 0.64$ & $38.61 \pm 0.41$ & $35.84 \pm 0.16$ \\
\hline 150 & $45.61 \pm 0.98$ & $43.81 \pm 0.26$ & $40.84 \pm 0.32$ \\
\hline 180 & $54.89 \pm 0.11$ & $48.79 \pm 0.16$ & $44.78 \pm 0.99$ \\
\hline
\end{tabular}

*All values are expressed as Mean $\pm \mathrm{SD}, \mathrm{n}=3$

Table 7: \% Drug Release in pH 6.8 phosphate buffer from batches ID2-ID4

\begin{tabular}{|c|c|c|c|}
\hline \multirow{2}{*}{$\begin{array}{c}\text { Time } \\
\text { (mins) }\end{array}$} & *Batch Code. \% Drug Release in pH 6.8 phosphate buffer \\
\cline { 2 - 4 } & ID2 & ID3 & ID4 \\
\hline 0 & 0 & 0 & 0 \\
\hline 15 & $23.43 \pm 0.12$ & $17.56 \pm 0.39$ & $15.43 \pm 0.75$ \\
\hline 30 & $38.55 \pm 0.29$ & $33.77 \pm 0.12$ & $26.22 \pm 0.69$ \\
\hline 45 & $52.23 \pm 0.40$ & $48.23 \pm 0.85$ & $43.65 \pm 0.33$ \\
\hline 60 & $62.65 \pm 0.81$ & $59.67 \pm 0.48$ & $53.78 \pm 0.15$ \\
\hline 90 & $71.77 \pm 0.28$ & $67.98 \pm 0.07$ & $59.54 \pm 0.44$ \\
\hline 120 & $78.45 \pm 0.14$ & $71.21 \pm 0.67$ & $66.78 \pm 0.11$ \\
\hline 150 & $81.77 \pm 0.38$ & $78.12 \pm 0.38$ & $70.90 \pm 0.18$ \\
\hline 180 & $85.98 \pm 0.29$ & $80.11 \pm 0.12$ & $75.19 \pm 0.54$ \\
\hline \multicolumn{4}{|c}{} \\
\hline
\end{tabular}

Table 6: \% Drug Release in pH 6.8 phosphate buffer from batches IC2-IC4

\begin{tabular}{|c|c|c|c|}
\hline \multirow{2}{*}{$\begin{array}{c}\text { Time } \\
\text { (mins) }\end{array}$} & \multicolumn{3}{|c|}{ Batch Code* \% Drug Release in pH 6.8 } \\
\cline { 2 - 4 } & IC2 & IC3 & IC4 \\
\hline 0 & 0 & 0 & 0 \\
\hline 15 & $17.89 \pm 0.63$ & $15.81 \pm 0.19$ & $14.05 \pm 0.76$ \\
\hline 30 & $26.71 \pm 0.81$ & $24.78 \pm 0.61$ & $23.91 \pm 0.34$ \\
\hline 45 & $34.87 \pm 0.16$ & $31.71 \pm 0.19$ & $29.36 \pm 0.17$ \\
\hline 60 & $43.91 \pm 0.12$ & $40.98 \pm 0.79$ & $38.14 \pm 0.54$ \\
\hline 90 & $52.13 \pm 0.16$ & $49.81 \pm 0.23$ & $46.84 \pm 0.14$ \\
\hline 120 & $61.89 \pm 0.34$ & $58.12 \pm 0.74$ & $54.12 \pm 0.79$ \\
\hline 150 & $72.12 \pm 0.15$ & $70.97 \pm 0.64$ & $66.98 \pm 0.12$ \\
\hline 180 & $82.16 \pm 0.98$ & $80.91 \pm 0.58$ & $78.01 \pm 0.74$ \\
\hline
\end{tabular}

$*$ All values are expressed as Mean $\pm \mathrm{SD}, \mathrm{n}=3$

Table 8: \% Drug Release of optimized batch ID2 in pH 6.8 PBS at 0 and 45 days

\begin{tabular}{|c|c|c|}
\hline \multirow{2}{*}{$\begin{array}{c}\text { Time } \\
\text { (min) }\end{array}$} & \% Drug release in PBS pH 6.8. ID2 \\
\cline { 2 - 3 } & 0 day* & 45 days* \\
\hline 0 & 0 & 0 \\
\hline 15 & $23.43 \pm 0.12$ & $21.35 \pm 0.79$ \\
\hline 30 & $38.55 \pm 0.29$ & $35.72 \pm 0.46$ \\
\hline 45 & $52.23 \pm 0.40$ & $50.23 \pm 0.49$ \\
\hline 60 & $62.65 \pm 0.81$ & $59.85 \pm 0.64$ \\
\hline 90 & $71.77 \pm 0.28$ & $68.23 \pm 0.29$ \\
\hline 120 & $78.45 \pm 0.14$ & $76.54 \pm 0.12$ \\
\hline 150 & $81.77 \pm 0.38$ & $78.24 \pm 0.58$ \\
\hline 180 & $85.98 \pm 0.29$ & $82.39 \pm 0.59$ \\
\hline \multicolumn{2}{|c|}{$*$ All values are expressed as Mean $\pm S D, n=3$} \\
\hline
\end{tabular}


Swastika Karwani et al. Int. Res. J. Pharm. 2013, 4 (5)

Table 9: Oral glucose tolerance test in non diabetic rats

\begin{tabular}{|c|c|c|c|c|}
\hline \multirow{2}{*}{$\begin{array}{c}\text { Treatment and dose } \\
(\mathbf{m g} / \mathbf{d l})\end{array}$} & \multicolumn{3}{|c|}{ Time (mins) (Monitoring after lag period of 150 mins of administration of beads) } \\
\cline { 2 - 5 } & $\mathbf{0}$ & $\mathbf{3 0}$ & $\mathbf{9 0}$ & $128.17 \pm 1.28$ \\
\hline Distilled water $(10 \mathrm{ml})$ & $69.63 \pm 0.93$ & $137.19 \pm 0.92$ & $97.28 \pm 1.38^{* *}$ & $112.21 \pm 0.13^{*}$ \\
\hline Standard Insulin & $70.10 \pm 1.81$ & $130.01 \pm 0.89^{* *}$ & $114.32 \pm 1.28$ & $89.28 \pm 0.71^{* *}$ \\
\hline Test-1 & $65.06 \pm 1.67$ & $132.28 \pm 3.12$ & $115.04 \pm 1.38^{*}$ & $104.48 \pm 1.06^{* *}$ \\
\hline Test-2 & $65.86 \pm 1.91$ & $130.9 \pm 0.68$ & $114.78 \pm 2.12^{*}$ & $103.27 \pm 3.12^{*}$ \\
\hline Test-3 & $70.49 \pm 1.28$ & $132.17 \pm 0.91$ & $106.18 \pm 4.12^{* *}$ & $97.17 \pm 4.28^{* *}$ \\
\hline Test-4 & $67.98 \pm 1.28$ & $130.74 \pm 0.76$ & $94.04 \pm 2.03^{* *}$ \\
\hline
\end{tabular}

All values are expressed as Mean \pm SEM, $\mathrm{n}=6, * *=$ Significance $\mathrm{p}<0.01$ and $*=$ Significance $\mathrm{p}<0.05$

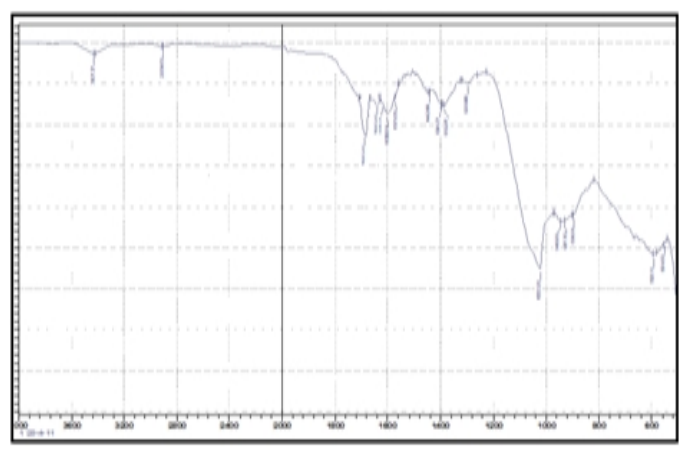

Figure 1: IR Spectra of acetylated chitosan (C1)

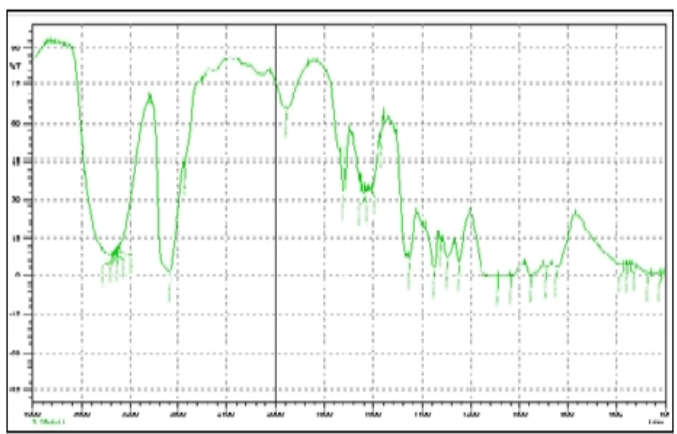

Figure 3: IR Spectra of PEG-g- chitosan(C3)

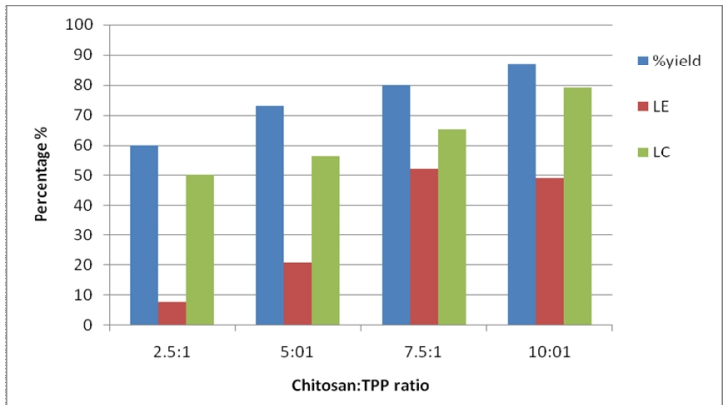

Figure 5: Percent yield, loading efficiency and loading capacity of chitosan nanoparticles

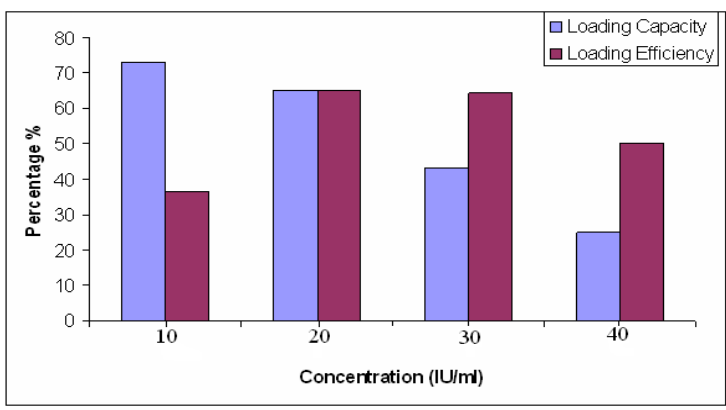

Figure 7: Percent yield, loading efficiency and loading capacity for Insulin

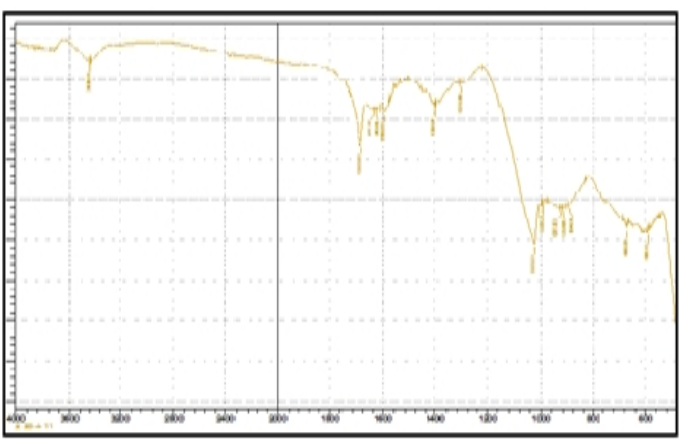

Figure 2: IR Spectra of LA-g- chitosan (C2)

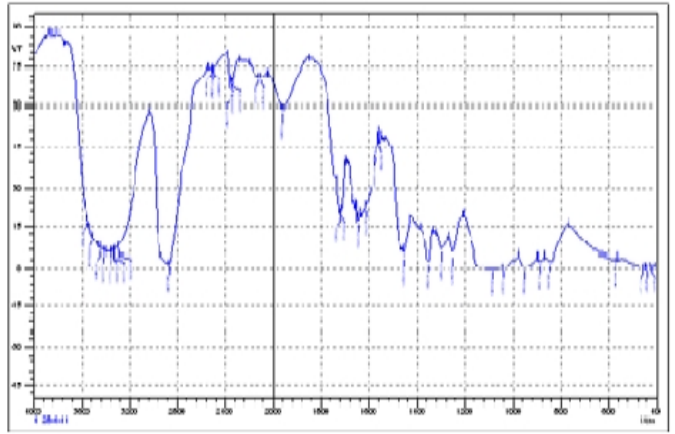

Figure 4: IR Spectra of LA-PEG-g- chitosan(C4)

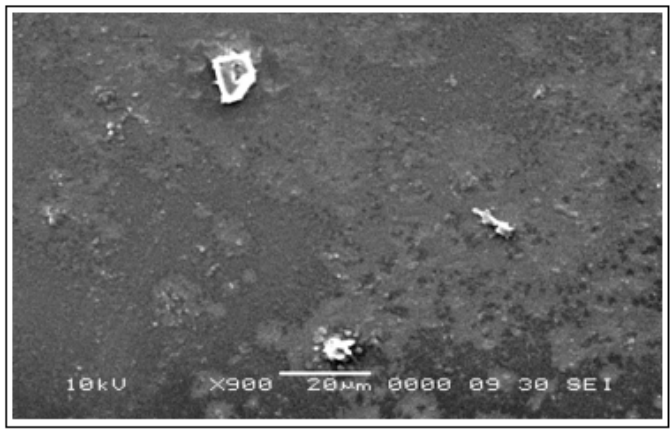

Figure 6: SEM images of chitosan nanoparticles

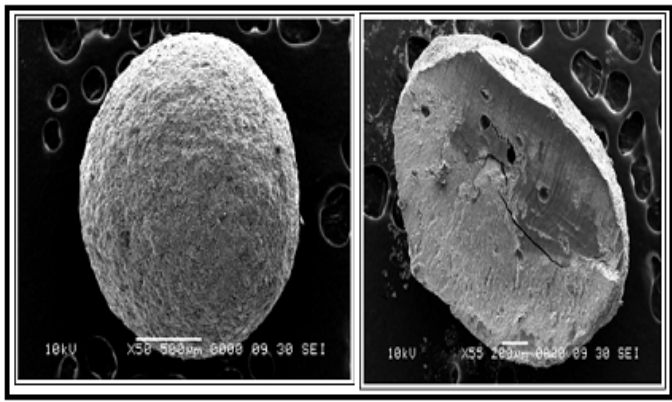

Figure 8: SEM images of surface section and T.S of the core alginate bead 


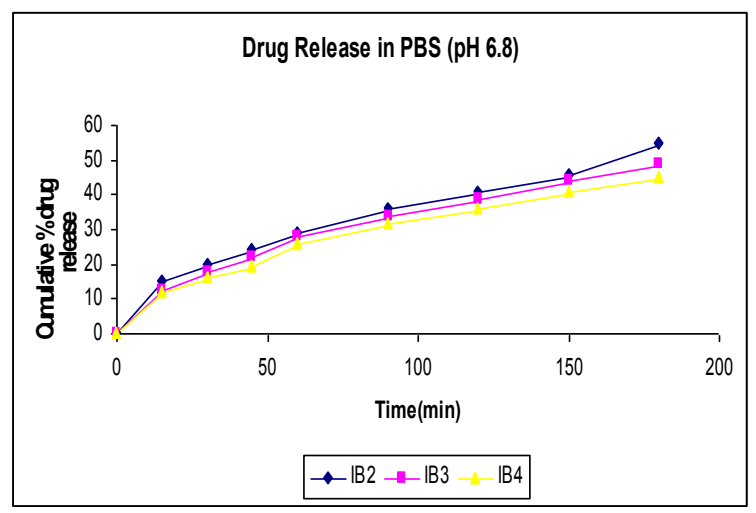

Figure 9: \% Drug Release in pH 6.8 phosphate buffer from alginate uncoated beads (IB2-IB4)

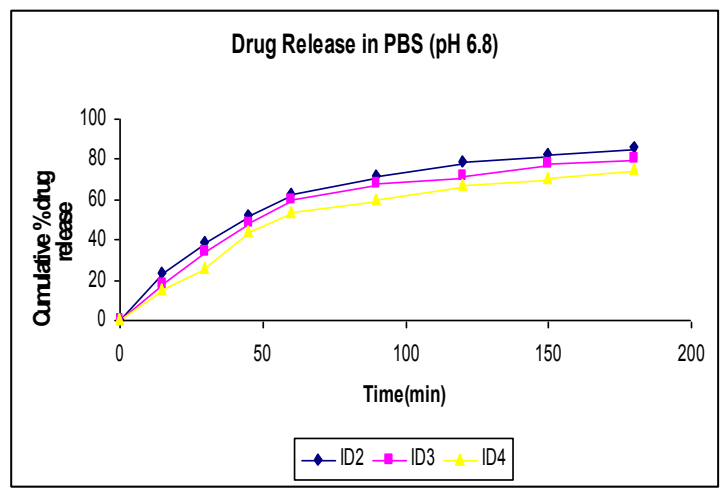

Figure 11: \% Drug Release in pH 6.8 phosphate buffer from alginate uncoated beads (ID2-ID4)

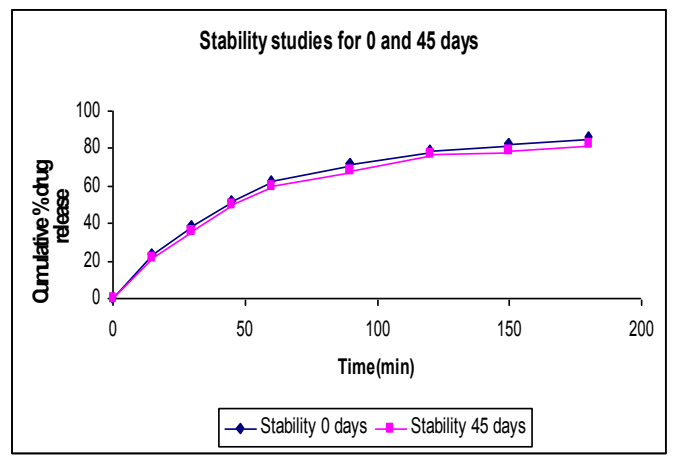

Figure 13: \% Drug Release of optimized batch ID2 in pH 6.8 PBS at 0 and 45 days

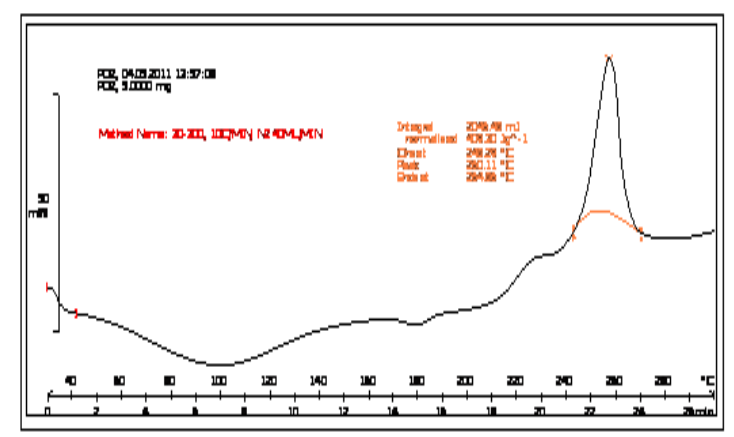

Figure 15: DSC thermogram of pure calcium alginate

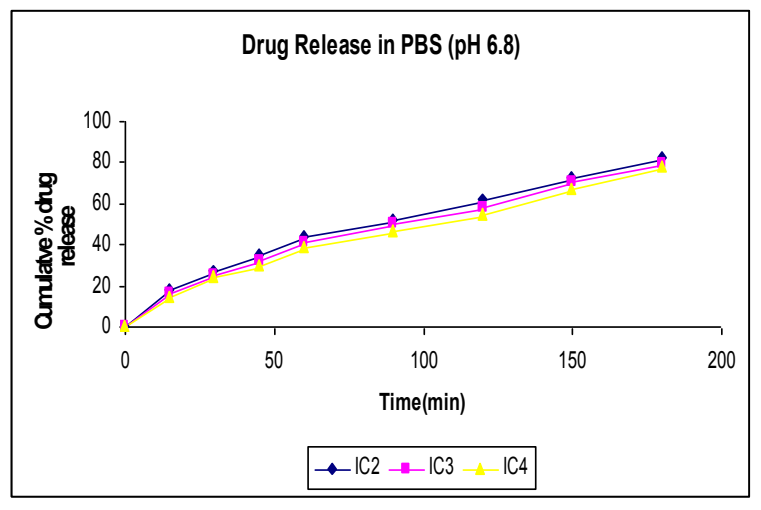

Figure 10: \% Drug Release in pH 6.8 phosphate buffer from alginate uncoated beads (IC2-IC4)\%

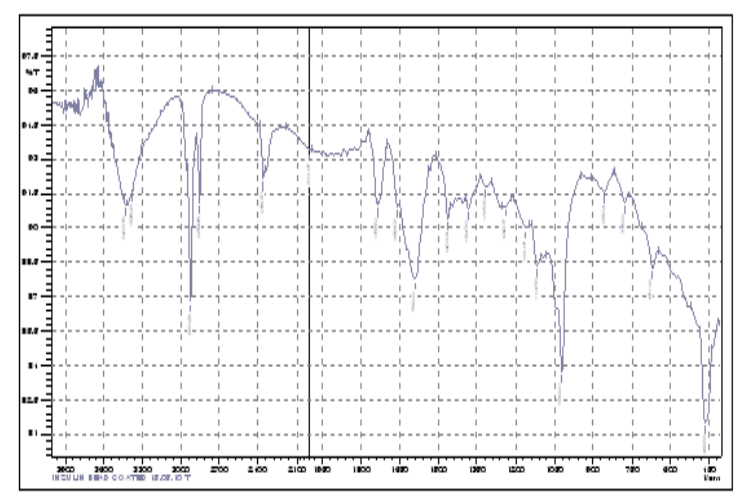

Figure 12: IR Spectra of Insulin formulation ID

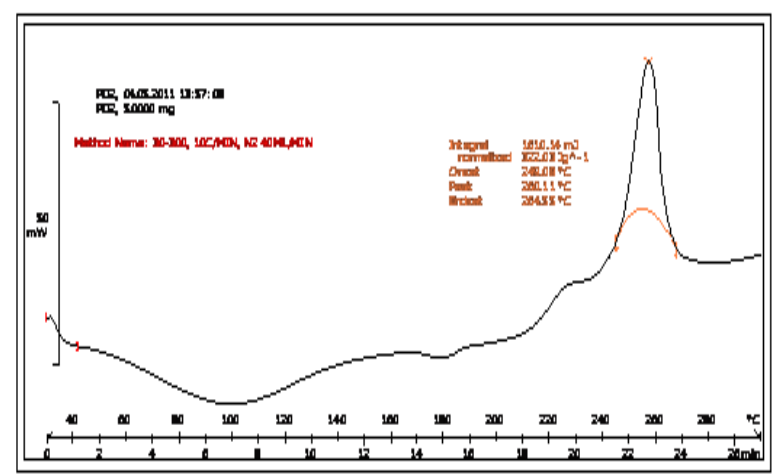

Figure 14: DSC thermogram of pure sodium alginate

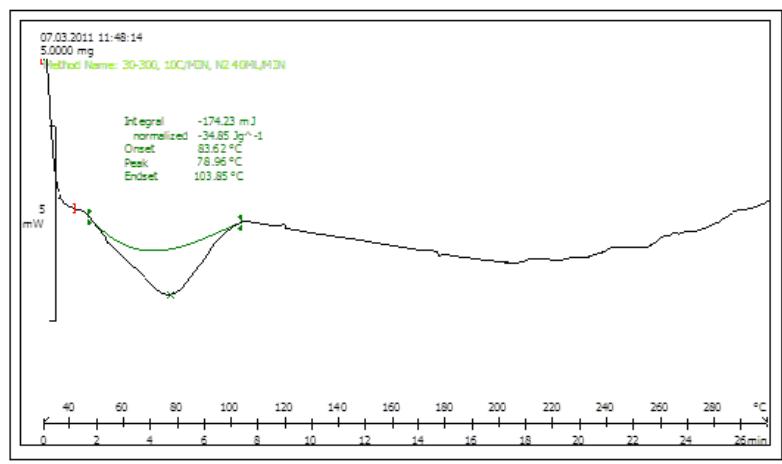

Figure 16: DSC thermogram of pure insulin 


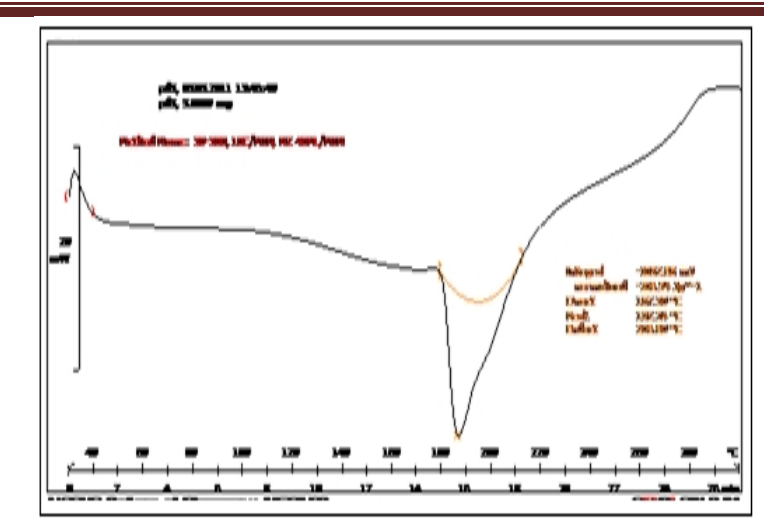

Figure 17: DSC thermogram of formulated alginate insulin loaded bead

\section{DSC analysis}

Thermograms were obtained using a Shimadzu DSC60system (Shimadzu). Samples were, powder crimped in a standard aluminium pan and heated from 30 to $300{ }^{\circ} \mathrm{C}$ at a heating constant rate of $10{ }^{\circ} \mathrm{C} / \mathrm{min}$ under constant purging of nitrogen at $10 \mathrm{ml} / \mathrm{min}$.

\section{Stability Studies}

Stability studies of the optimized formulations were carried out to know whether the chemical change or degradation of the active ingredient has occurred. This may lower the therapeutic potency of active ingredient over storage period. Whether any toxic degradation product has formed which may be undesirable and gross changes in the physical form of the dosage form have occurred implying poor or substandard quality of ingredients. To assess the drug and formulation stability, stability studies were done according to ICH guidelines. Optimized formulation sealed in aluminum packaging coated inside with polyethylene, and various replicates were kept in the humidity chamber maintained at $40^{\circ} \mathrm{C}$ and $75 \% \mathrm{RH}$ for 45 days. At the end of studies, samples were analyzed for the physical appearance, drug content and drug release studies.

In-vivo Animal activity study Oral Glucose Tolerance Test (OGTT)

Experimental animals- Albino rats of Wistar strain weighing 150-200 g were obtained. Animals of either sex were housed in groups of five under standard laboratory conditions with free access to standard pellet diet and water.

\section{Procedure}

The overnight fasted animals were divided into Three groups $(\mathrm{n}=6)$. The animals were given $10 \%$ Glucose Solution 0 minutes after drug treatment.

1. Group-I (Control): The animals of this group received Distilled water.

2. Group-II (Standard Insulin): The animals of this group received Standard Insulin $0.525 \mathrm{IU} / \mathrm{kg}$ S.C.

3. Group-III, IV, V and VI (Insulin Beads): The animals of this group received Insulin beads $1.0 \mathrm{IU} / \mathrm{kg}$, p.o, $3 \mathrm{hrs}$ before administration of standard insulin S.C. to Group-II. After the lag period of 150 minutes of administration of beads the $0^{\text {th }}, 30^{\text {th }}, 90^{\text {th }}$ and $150^{\text {th }}$ minutes blood was collected by puncturing retro-orbital plexus under light ether anesthesia by using fine glass capillary. Plasma was separated by centrifugation. Plasma glucose level was determined by GOD/POD method ${ }^{21-23}$.

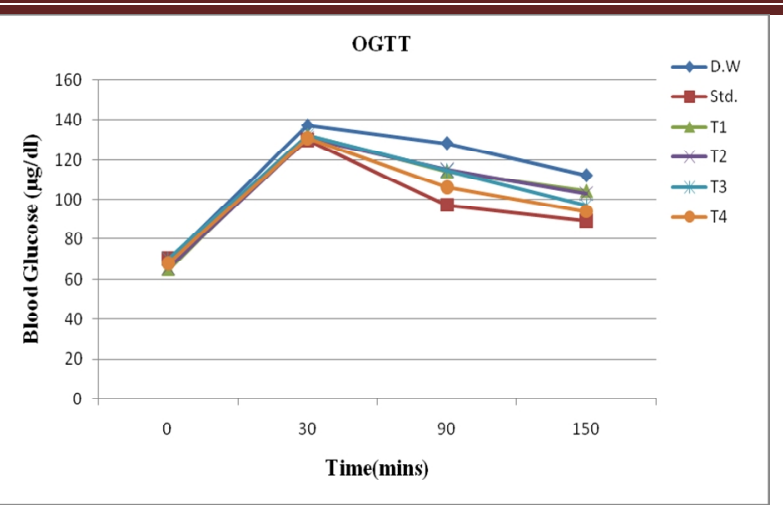

Figure 18: Plasma glucose level in non diabetic rats at $0,30,90$ and $150 \mathrm{~min}$ and for beads after a lag period of $150 \mathrm{mins}$ of administration

\section{RESULTS AND DISCUSSIONS}

\section{Characterization of modified polymers}

IR spectra of acetylated chitosan copolymer

The IR Spectra of acetylated chitosan obtained on a FTIR with diffused reflectance assembly is shown in Figure 1. It is similar with that reported in literature.

\section{IR spectra of LA-g-chitosan copolymer}

The IR Spectra of LA-g- chitosan obtained on a FTIR with diffused reflectance assembly is shown in Figure 2. It is similar with that reported in literature.

\section{IR spectra of PEG-g- chitosan copolymer}

The IR Spectra of PEG-g- chitosan obtained on a FTIR with diffused reflectance assembly is shown in Figure 3. It is similar with that reported in literature.

\section{IR spectra of LA-PEG-g- chitosan copolymer}

The IR Spectra of LA-PEG-g- chitosan obtained on a FTIR with diffused reflectance assembly is shown in Figure 4. It is similar with that reported in literature.

\section{Evaluation of chitosan nanoparticles \\ Percent yield, loading efficiency (LE) and loading capacity (LC)}

As concluded in Table 3 and Figure 5. \% yield, loading efficiency and loading capacity of the nanoparticles were affected by the variable chitosan concentration. This might be due to the concentration of TPP taken as constant to achieve the chitosan: TPP ratio between $6: 1$ to $10: 1$ for effective protein association and loading. Thus NANO (N4) batch having chitosan: TPP $(10: 1)$ ratio was selected for further studies as it showed highest \% yield, loading efficiency and capacity Table 3 and Figure 5.

Surface morphology and particle size analysis by scanning electron microscopy (SEM)

The optimized batch of chitosan nanoparticles (NANO N4) was characterized by SEM. Scanning electron microphotograph of chitosan nanoparticles is given in fig.no.6. According to Figure 6, chitosan nanoparticles were irregular with size ranging from 100 to $520 \mathrm{~nm}$.

Size of nanoparticles: N1 $=309.9, \mathrm{~N} 2=428.9, \mathrm{~N} 3=392.2$ and $\mathrm{N} 4=519$ 
Drug loading studies on optimized chitosan nanoparticles Loading Efficiency (LE) and Loading Capacity (LC) studies for Insulin

To optimize dose equivalent concentration of Insulin loaded on the nanoparticles various concentrations of Insulin solution from 10-40 IU/ml were incubated with the optimized batch of chitosan nanoparticles, the LE and LC was studied. The loading efficiency was greater than $70 \%$ for Insulin concentration $10 \mathrm{IU} / \mathrm{ml}$. The loading efficiency significantly decreased below $65 \%$ when Insulin concentration was increased above $20 \mathrm{IU} / \mathrm{ml}$. This phenomenon might be attributed to the saturation of loading efficiency which was achieved at concentration of Insulin above $20 \mathrm{IU} / \mathrm{ml}$; the more addition of insulin onto chitosan nanoparticles lead to the great decrease in loading efficiency (LE). Meanwhile, loading capacity increased from $36 \%$ to $65 \%$ as the Insulin concentration increased from $10 \mathrm{IU} / \mathrm{ml}$ to $20 \mathrm{IU} / \mathrm{ml}$ as given in Figure 7. Thus, Insulin concentration of $20 \mathrm{IU} / \mathrm{ml}$ was selected for further studies.

\section{Evaluation of alginate beads}

Morphology, percent yield and particle size analysis of beads

Morphology of uncoated beads was examined by microscopic study. SEM of surface section and T.S of the core sodium alginate beads is given in the Figure 8. Prepared beads were distinguished by its spherical nature. Particle size was determined by Digital Vernier Calliper. The Morphology, Percent yield and Particle size analysis of beads is given in Table 4.

\section{Alginate uncoated beads batches A1-A4}

In the batches A1-A4 no uniform beads were formed, this might be due to the less viscosity of the sodium alginate solution $(2 \% \mathrm{w} / \mathrm{v})$ as given in Table 4 .

\section{Alginate uncoated beads batches B1, C1, D1}

In the batches B1, C1 and D1 uneven beads were formed, this might be due to the insufficient hardening time ( 5 minutes) in $\mathrm{CaCl}_{2}$ solution as given in Table 4 .

\section{Insulin release from uncoated beads in $\mathrm{pH} 6.8$ phosphate buffer}

Percentage insulin release of alginate uncoated beads batches IB2-IB4

The release profiles in phosphate buffer solution $\mathrm{pH} 6.8$ of Insulin loaded chitosan nanoparticles entrapped in IB2-IB4 batches of uncoated alginate beads are shown in Table 5 and Figure 9. As depicted in Figure 9, Insulin release of about $54.89 \%, 48.79 \%$ and $44.78 \%$ was observed in batches IB2, IB3 and IB4 respectively. The delayed release of insulin from the batches might be due to increase in the hardening time from 10 to 20 minutes respectively.

Percentage insulin release of alginate uncoated beads batches IC2-IC4

The release profiles in phosphate buffer solution $\mathrm{pH} 6.8$ of Insulin loaded chitosan nanoparticles entrapped in IC2-IC4 batches of uncoated alginate beads are shown in Table 6 and Figure 10. As depicted in fig.no.10, Insulin release of about $82.16 \%, 80.91 \%$ and $78.01 \%$ was observed in batches IC2, IC3 and IC4 respectively. The release might be attributed to the water uptake/ swellable nature of alginate beads. The release profile of Insulin batch IC4 given in Table 6 and
Figure 10. The delayed release of insulin from the batch IC4 might be due to increase in the hardening time from 10 to 20 minutes.

Percentage insulin release of alginate uncoated beads batches ID2-ID4

The release profiles in phosphate buffer solution $\mathrm{pH} 6.8$ of Insulin loaded chitosan nanoparticles entrapped in ID2-ID4 batches of uncoated alginate beads are shown in Table 7 and Figure 11. As depicted in Figure 11, Insulin release of about $85.98 \%, 80.11 \%$ and $75.19 \%$ was observed in batches ID2, ID3 and ID4 respectively. The release might be attributed to the water uptake/ swellable nature of alginate beads. The release profile of Insulin batches ID2 and ID3 above 80\% and ID4 given in Table 7 and Figure 11 showed release of $75 \%$. This might be due to increase in hardening time.

Selection of optimized batch of insulin loaded chitosan nanoparticles entrapped uncoated alginate beads

From the release profiles in phosphate buffer solution $\mathrm{pH} 6.8$ of Insulin loaded chitosan nanoparticles entrapped in batches of uncoated alginate beads ID2, ID3, IC2 and IC3 were selected as the optimized batches. The mean content uniformity of optimized batches ID2, ID3, IC2 and IC3 of insulin was found to be $85.21 \%, 80.22 \%, 82.35 \%$ and $80.90 \%$ respectively.

\section{IR study of optimized formulation of Insulin ID2}

IR studies for formulations were done to confirm presence of Insulin in uncoated sodium alginate beads. IR spectrum was obtained on FTIR with diffused reflectance assembly shown in Figure 12. The encapsulation of insulin in ID2 formulation was confirmed from the presence of IR spectra.

\section{Stability studies}

Intermediate stability studies were carried out for 0 and 45 days on optimized formulations. The samples were stored at $40^{\circ} \mathrm{C} \pm 2^{\circ} \mathrm{C}$ and $75 \% \pm 5 \% \mathrm{RH}$ to assess their stability. The protocol of stability studies were in compliance with $\mathrm{ICH}$ guidelines for stability testing intended for the global market. No sticking of beads was observed for both optimized formulations. The dissolution profiles for 0 and 45 days that were placed for Stability studies are studied.

\section{Stability studies of Insulin}

\section{Content uniformity of insulin}

The mean content uniformity of optimized insulin ID2 after 0 and 45 days was found to be $85.14 \%$ and $80.12 \%$ respectively.

\section{In-vitro Drug release studies of optimized batch ID2 in} pH 6.8 PBS at 0 and 45 days

The release profiles in PBS pH 6.8 of optimized Insulin formulation ID2 after 0 and 45 days are shown in Table 8 and Figure 13 As depicted in Figure 13, insulin release of about $85.98 \%$ and $82.39 \%$ was observed at the end of 180 minutes for both 0 and 45 days respectively. This indicates that the optimized Insulin formulation ID2 was stable till 45 days.

\section{Differential Scanning Colorimetric Analysis}

The differential scanning colorimetry was carried out for the pure sodium alginate, calcium alginate, pure insulin and selected formulation of alginate insulin loaded beads to study compatibility or any interaction of drug and polymer in matrix beads and is shown in fig.no.14, 15, 16 and 17 
respectively. The thermogram of beads indicated endothermic peak at $83.2{ }^{0} \mathrm{C}$ for insulin corresponding to its melting point. There was no significant change in the position of peak and its intensity. Thus, DSC study showed no interaction between the drug and polymers.

\section{In-vivo Animal activity study Oral Glucose Tolerance Test (OGTT)}

Insulin-loaded bead were administered orally to overnight fasted Non diabetic rats. The reduction of the initial blood glucose levels versus time after intragastric insulin beads and subcutaneous administration of insulin is depicted in Figure 18 and Table 9. After subcutaneous administration of insulin the blood glucose level significantly $(* * p<0.01)$ decreases to $130.01,97.28$, and $89.28 \mathrm{mg} / \mathrm{dl}$ as compared with control group 137.91, 128.17 and $112.21 \mathrm{mg} / \mathrm{dl}$ after 30,90 and 150 min. respectively.

After the administration of intragastric insulin beads the blood glucose level, the decrease started after the lag period of 150 minutes and decreased up to $30^{\text {th }}$ min as compared with control group while after that significant $(* \mathrm{p}<0.05)$ decrease was showed 114.32 and $104.48 \mathrm{mg} / \mathrm{dl}$ in T1, 115.04 and $130.27 \mathrm{mg} / \mathrm{dl}$ in $\mathrm{T} 2,114.78$ and $97.17 \mathrm{mg} / \mathrm{dl}$ in $\mathrm{T} 3$ and 106.18 and $94.04 \mathrm{md} / \mathrm{dl}$ in T4 as compared with control group 128.17 and $112.21 \mathrm{mg} / \mathrm{dl}$ after 90 and $150 \mathrm{~min}$. respectively.

From above observation it has been concluded that the intragastric insulin beads showed onset of action after lag period of 150 minutes at $30^{\text {th }}$ min and the better results were shown by $\mathrm{T} 4$.

The internal insulin decrease was found to be $0.3 \mathrm{IU} .41 \mu \mathrm{g} / \mathrm{dl}$ which was the decrease in glucose level after $150^{\text {th }} \mathrm{min}$ of administration of standard insulin $(0.52 \mathrm{IU})$ and for $1 \mathrm{IU}$ was equivalent to $78.8 \mu \mathrm{g} / \mathrm{dl}$. Thus the decrease in glucose level on administration of insulin beads T1, T2, T3 and T4 after the lag period of 150 minutes were calculated. Table.no.10 shows the $\%$ glucose drop after administration of standard insulin and test insulin beads T1, T2, T3 and T4.

\section{REFERENCES}

1. Ieva E, Trapani A, Cioffi N. Analytical characterization of chitosan nanoparticles for peptide drug delivery applications, Anal Bioanal Chem 2009; 393: 207-215. http://dx.doi.org/10.1007/s00216-008-2463-4

2. http://en.wikipedia.org/wiki/Protein (Access Date - 9 February 2013)

3. http://en.wikipedia.org/wiki/Insulin (Access Date - 13 February 2013)

4. Yan W. Chitosan nanoparticles as a novel delivery system for ammonium glycyrrhizinate, International Journal of Pharmaceutics 2005; 295: 235-245. http://dx.doi.org/10.1016/j.ijpharm.2005.01.042

5. Morishita M, Peppas NA. Is the oral route possible for peptide and protein drug delivery? Drug discovery today 2006; 11: 905-910. http://dx.doi.org/10.1016/j.drudis.2006.08.005
6. Arhewoh IM. Optimizing oral systems for the delivery of therapeutic proteins and peptides, African Journal of Biotechnology 2005; 4 (13): 1591-1597.

7. Sashiwa H, Shigemasa Y. Chemical modification of chitin and chitosan 2: prepration and water soluble property of $\mathrm{N}$-acylated or $\mathrm{N}$-alkylated partially deacetylated chitins, Carbohydrate Polymers 2009; 39: 127138. http://dx.doi.org/10.1016/S0144-8617(98)00167-2

8. Yang H. Synthesis and characterization of chitosan-g-poly-(D,L-lactic acid) copolymer, Chines chemical letters 2005; 16: 123-126.

9. Bhattaraj N. Chitosan and lactic acid-grafted chitosan nanoparticles as carriers for prolonged drug delivery, International Journal of Nanomedicine 2006; 181-187. http://dx.doi.org/ 10.2147/nano.2006.1.2. 181

10. Natalija G, Makuska R. Synthesis and study of water-soluble chitosanO-poly (ethylene glycol) graft copolymers, European polymer journal 2009; 40: 685-691.

11. Amiji MM. Synthesis of anionic poly(ethylene glycol) derivative for chitosan surface modification in blood-contacting applications, Carbohydrate Polymers 1997; 32: 329-332. http://dx.doi.org/10.1016/ S0144-8617(97)00006-4

12. Yaoa F. A study on cytocompatible poly(chitosan-g-l-lactic acid), Polymer 2003; 6435-6441 http://dx.doi.org/10.1016/S00323861(03)00676-1

13. Xiong FU, Yan. Water-soluble chitosan nanoparticles as a novel carrier system for protein delivery, Chinese science bulletin 2007; 52: 883-889. http://dx.doi.org/10.1007/s11434-007-0127-y

14. Cuisine Innovation - www.cuisineinnovation.fr (Access Date - 17 February 2013)

15. http://www.scitopics.com/The oral delivery of therapeutic proteins.ht ml. (Access Date - 19 February 2013)

16. Mandal S. Development and evaluation of calcium alginate beads prepared by sequential and simultaneous methods, Brazilian journal of pharmaceutical sciences 2010; 46: 785-793.

17. Gazori T, Mohammad RK, Ebrahim A, Parisa Y, Alireza N, Ismaeil H. Evaluation of Alginate/Chitosan nanoparticles as antisense delivery vector: Formulation, optimization and in vitro characterization 2009; 77 : 599-606.

18. Takka S, Aybige G. Evaluation of chitosan/alginate beads using experimental design: formulation and in vitro characterization. American association of pharmaceutical scientist 2010; 11(1): 460-466.

19. Patel FM. Release of metformin hydrochloride from ispaghula sodium alginate beads adhered cock intestinal mucosa. International Journal of Current Pharmaceutical Research 2011; 3(3).

20. Jain D, Panda AK, Majumdar DK. Eudragit S100 entrapped insulin microspheres for oral delivery. American association of pharmaceutical scientist Pharm Sci Tech 2005; 1-27.

21. S.R. Keller. Insulin Tolerance Test protocol. Cell 1997; 88: 561-572.

22. S.V. Tembhurne, D.M. Sakarkar. Hypoglycemic effects of fruit juice of murraya koenigii (l) in alloxan induced diabetic mice. International journal of pharma tech research CODEN (USA) IJPRIF 2009; 1: 15891593.

23. Panchal II. Design, synthesis and biological evaluation of some substituted sulphonyl urea/ guanidine derivatives as hypoglycemic agents. J.chem..pharm 2010; 609-617.

\section{Cite this article as:}

Swastika Karwani, Rabindra Nanda and Jyoti Nirmal. Chemical modification of Chitosan and formulation of its nanoparticles for protein drug delivery system. Int. Res. J. Pharm. 2013; 4(5):165-172 